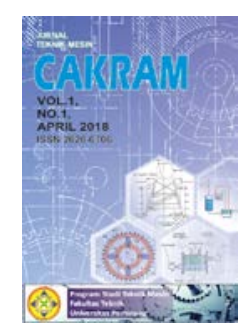

\title{
ANALISA KERUSAKAN PLATE WIRE PADA PROSES COILING
}

\author{
Jaja Miharja $^{1)}$ \\ ${ }^{1}$ Program Studi Teknik Mesin, Universitas Pamulang, Jl. Surya Kencana No.1, Tangerang Selatan, Indonesia \\ E-mail : dosen01292@unpam.ac.id
}

Masuk : 8 Maret 2020

Direvisi : 25 Maret 2020

Disetujui : 30 Maret 2020

\begin{abstract}
Plate Wire mengalami kerusakan ketika akan dilakukan proses spiral setelah di proses rolling dari solid wire. Kerusakan yang terjadi patah pada saat awal proses spiral. Dengan pengamatan visual kerusakan Plate Wire, harus dilakukan pengujian - pengujian untuk memastikan penyebab kerusakan tersebut meliputi pengujian komposisi material, uji kekerasan, dan uji metalografi dan pengamatan struktur mikro. Analisa hasil pengujian di bandingkan dengan literatur, standart material internasional, dan faktor - faktor pendukung lainnya diharapkan mampu menjadi referensi pengambilan keputusan yang tepat tentang penyebab utama kerusakan. Hasil uji komposisi kima yang paling berpengaruh unsur karbon (C) pada $(0,648 \%$ C) tidak sesuai dengan standar JIS G4051 2007 (0.42 - 0,48\%C), dan rata - rata nilai kekerasan sebesar 488,666 HV tidak sesuai dengan standar JIS G4051 2007 (160 - 230) HV. Kesimpulan penyebab utama kerusakan digunakan untuk pengembangan kwalitas Plate Wire serta upaya improvement sifat material untuk memperpanjang umur material (life time) meliputi heat treatment, komposisi material, manufaktur, serta penerapan prosedur kerja yang tepat.
\end{abstract}

Kata kunci: Plate Wire,Rolling, Kerusakan, Pengujian

\begin{abstract}
Abstrak: Plate wire damaged when will be conducted a process of spiral after in the process of rolling of solid wire .Damage that occurs broken at the beginning of spiral process. With visual observations of plate wire damage, tests must be carried out to ensure the cause of the damage includes testing the composition of the material, hardness test, and metallographic test and micro structure observation .Analysis of test results compare with literature, international material standards, and other supporting factors is expected to be a reference for making the right decision about the main causes of damage. The results of the chemical composition of the most influential carbon (C) at $(0.648 \%$ C) were not in accordance with the 2007 JIS G4051 standard $(0.42-0.48 \%$ C), and the average hardness value of $488.666 \mathrm{HV}$ was not in accordance with the JIS G4051 standard 2007 (160 - 230) $H V$. Conclusions the main cause of damage are used to develop quality of the plate wire as well as efforts to improve material properties to extend the life of material ( life time ) including heat treatment, the composition of material , manufacturing, and the application of appropriate work procedures.
\end{abstract}

Keywords: Plate wire, Rolling, Damage,Testing

\section{PENDAHULUAN}

Plate Wire merupakan kabel berbentuk plat hasil proses pengerolan berupa kabel pejal yang selanjutnya akan di proses spiral membentuk spring dengan mesin coiling. Material plate wire adalah baja S45C. Kerusakan yang terjadi adalah patah getas pada saat awal proses spiral dengan mesin coiling setelah proses rolling. Kerusakan berlangsung terus menerus sehingga produksi terhenti,dan menimbulkan kerugian yang 
besar. Kerugian perusahaan akibat kerusakan tersebut meliputi biaya material yang terbuang, terlambatnya proses produksi lanjutan dan tertundanya pengiriman ke konsumen (customer). Kerusakan menyebabkan berhentinya proses produksi karena penggantian atau perbaikan memerlukan waktu yang \pm 30 menit.

Dari hasil pengamatan visual pada Plate wire menunjukkan bahwa kerusakan terjadi pada area plat yang mengalami tekukan. Guna memastikan komposisi material serta faktor - faktor lainnya perlu dilakukan pengkajian kekuatan material. Pengujian yang dilakukan adalah uji komposisi material, uji kekerasan, uji tarik dan uji metalografi dan melakukan pengamatan struktur mikro. Data - data hasil pemeriksaan dan pengujian diharapkan menjadi referensi analisa kerusakan dan pengambilan keputusan yang tepat.

Berdasarkan latar belakang diatas, dapat dirumuskan permasalahan yang dijadikan kajian studi atau penelitian untuk pembuatan tesis ini, maka penulis memfokuskan pada masalah kerusakan plat wire dan optimasi usaha meningkatkan kwalitas material Plate Wire.

Secara visual pada plat wire di temukan kerusakan mayoritas terjadi pada saat proeses awal coiling plat wire. Kerusakan tersebut menyebabkan berhentinya proses produksi dan kerugian material plat wire sehingga produktifitas produksi terganggu secara signifikan. Penyebab kerusakan atau kegagalan harus ditemukan sedini mungkin untuk mencegah kerugian material yang lebih banyak dan menjadi referensi untuk komplain ke suplier.

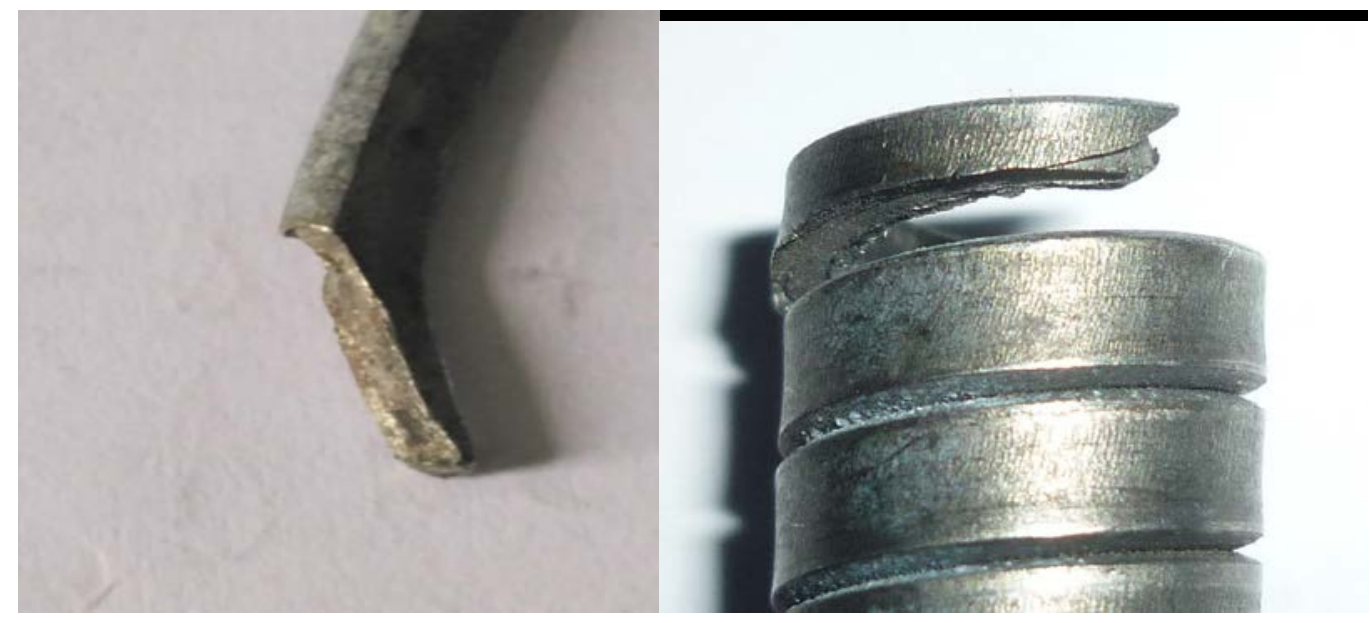

Gambar 1. Kerusakan plat wire, kiri: patahan kawat lurus, kanan : patahan kawat melingkar

\section{METODOLOGI}

Dalam penelitian ini pengumpulan dan analisa data dilakukan dengan beberapa metode sebagai berikut

1) Identifikasi Masalah dan Pengumpulan Data

Pengumpulan data primer dan pendukung dilakukan dengan cara inspeksi lapangan, pengambilan data operasi, pengambilan material dan pemeriksaan kerusakan plat wire secara visual.

2) Studi Literatur, Pengamatan dan Pengujian

Dalam penelitian penyebab terjadinya kerusakan dari plat wire ini dilakukan beberapa pengamatan dan pengujian di sesuaikan dengan berbagai pustaka maupun literature yang terkait dengan obyek penelitan yang bertujuan untuk mencari penyebab yang terjadi kerusakan plat wire tersebut berdasarkan dengan pemahaman keilmuan dan standart yang berlaku.

3) Pemeriksaan dan pengujian terhadap plat wire meliputi pengujian secara visual (fraktografi), pengujian metalografi, uji kekerasan, pengujian komposisi kimia. 


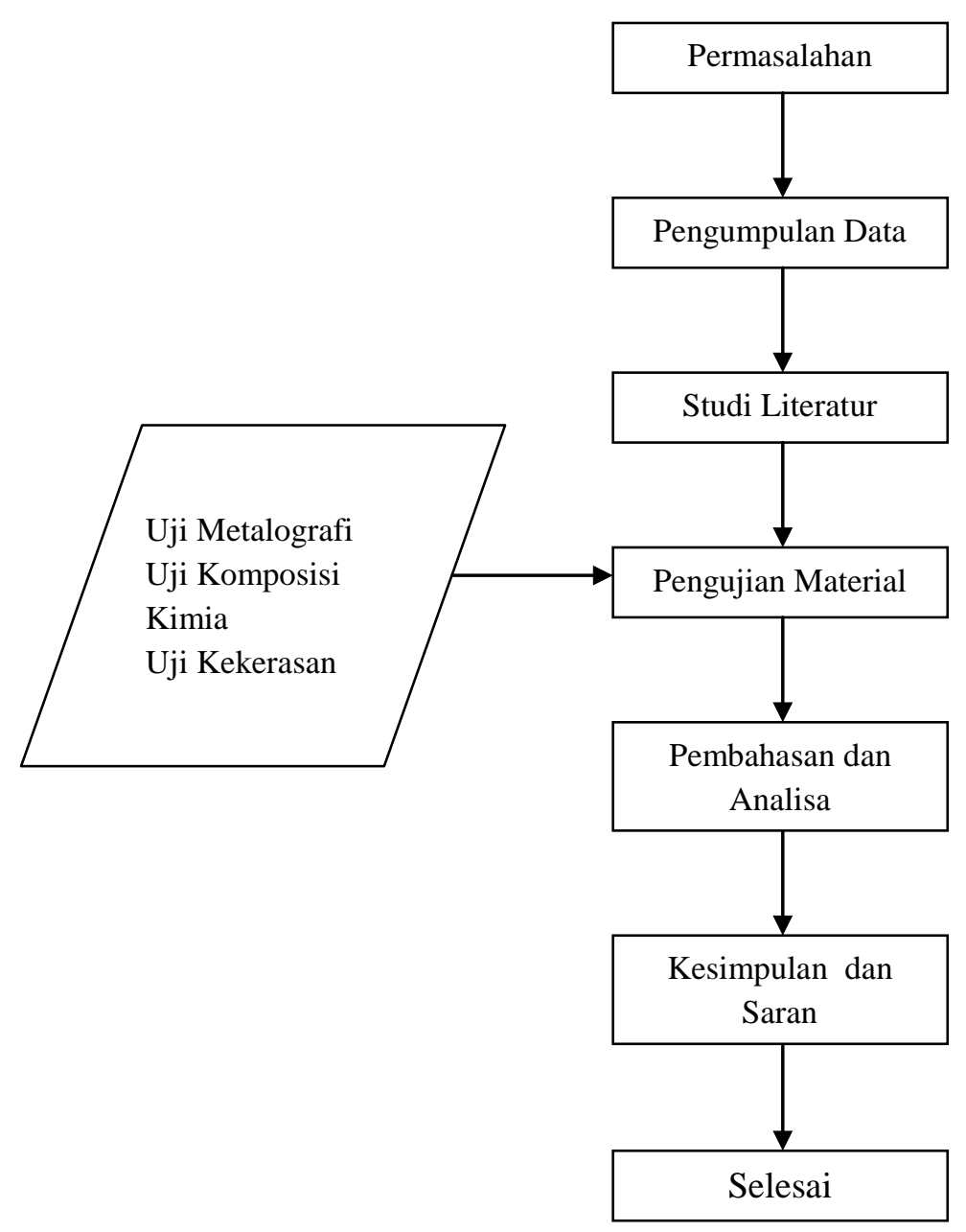

Gambar 2. Diagram alur Penelitian

Metodologi yang digunakan dalam penelitian ini diawali dengan melakukan pengumpulan data primer dan sekunder melalui inspeksi lapangan, pengambilan data visual, sampel material uji, pengujian, studi literatur untuk mendukung pembuktian hipotesa, pengolahan data, analisa sampai dengan mendapatkan penyebab terjadinya kerusakan dan penentuan kelayakan material plate wire.

\section{HASIL DAN PEMBAHASAN}

Untuk mengetahui penyebab kerusakan maka harus dilakukan pemeriksaan dan pengujian antara lain:
a). Pemeriksaan fraktografi
b). Pemeriksaan metalografi
c). Uji kekerasan
d). Uji komposisi kimia

Hasil pengamatan visual serta data-data kerusakan yang didapatkan sebagai berikut:

Pemeriksaan obyek secara langsung (Inspeksi visual) dilakukan untuk memastikan terjadinya kerusakan agar mendapatkan data - data otentik untuk proses analisa kerusakan dan upaya perbaikan. Hasil pengamatan visual serta data-data kerusakan yang didapatkan sebagai berikut: 
Jurnal Teknik Mesin: CAKRAM 2020

Jaja Miharja, Analisa Kerusakan Plate Wire Pada Proses Coiling

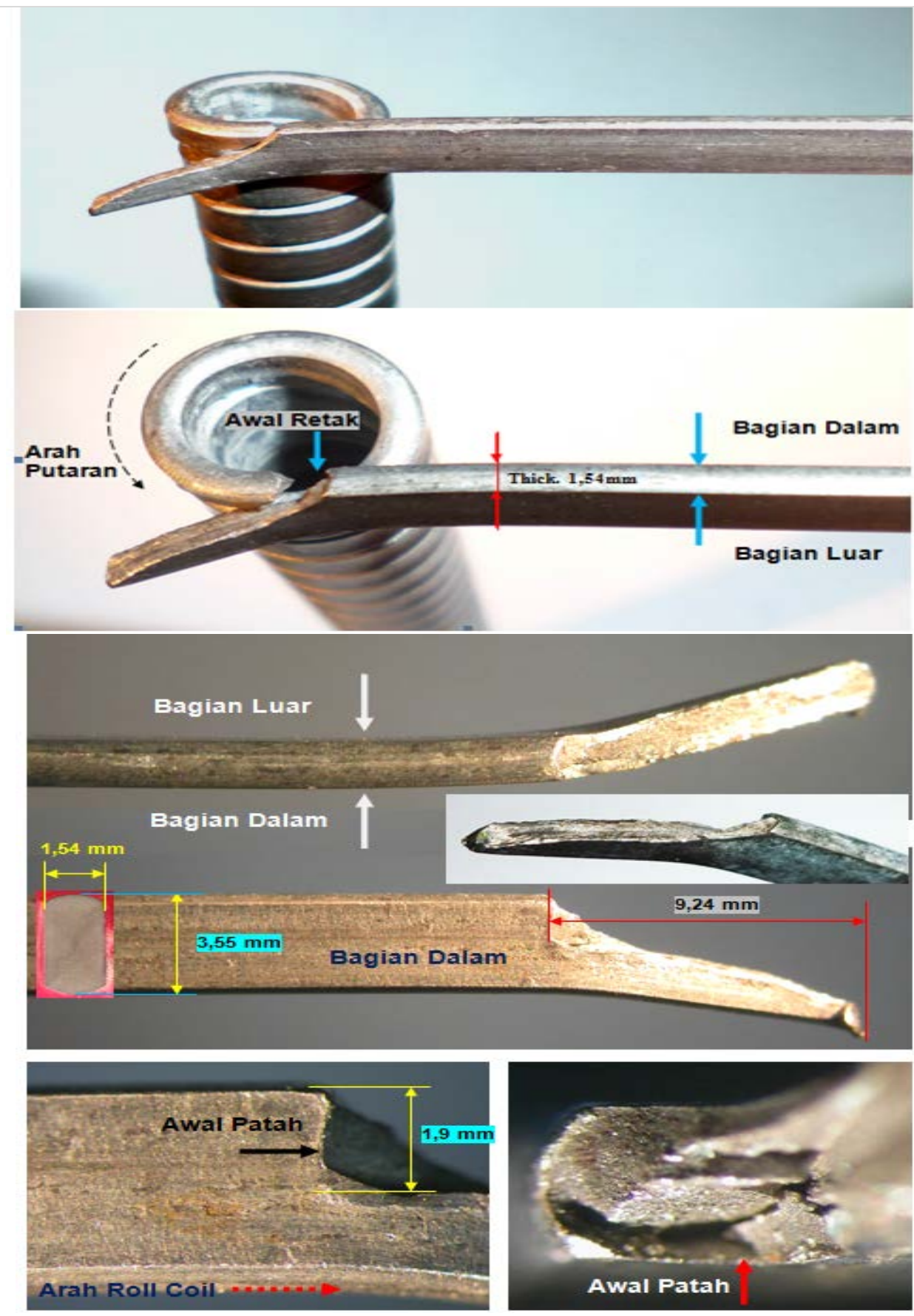

Gambar 3. Photo makro wire coil yang mengalami kerusakan/patah pada saat proses operasi berlangsung.

Dari pengamatan visual pada gambar 3 dapat di simpulkan patah terjadi pada saat proses pengerolan dari bagian dalam. Pemeriksaan makro terhadap permukaan patahan mempunyai bentuk patah statik dan dimulai dari bagian tengah lebar kawat 
Jurnal Teknik Mesin: CAKRAM 2020

Jaja Miharja, Analisa Kerusakan Plate Wire Pada Proses Coiling

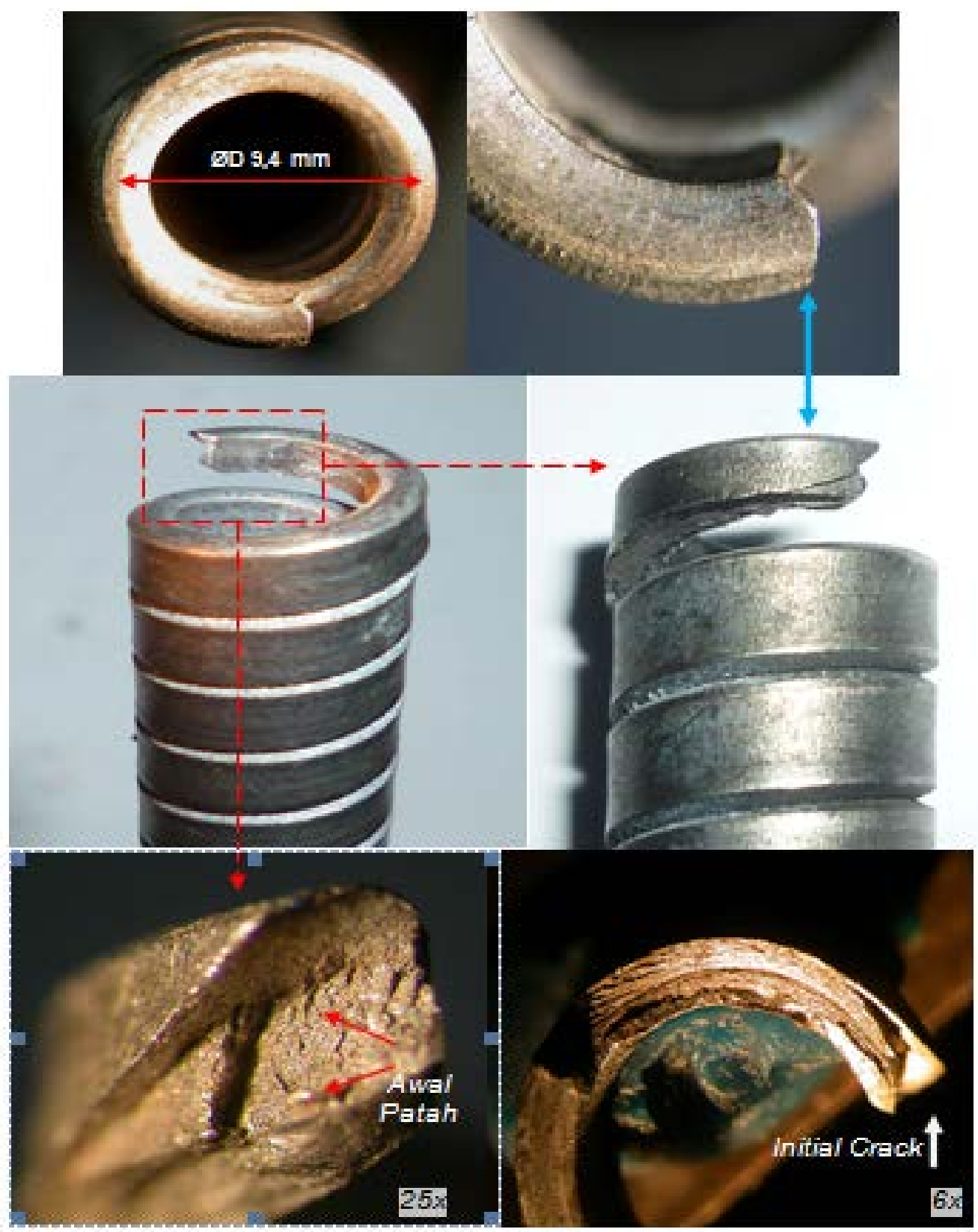

Gambar 4. Photo makro wire coil (kawat lurus)

Dari pengamatan visual dapat diketahui patah terjadi pada saat proses pengerolan dari bagian dalam. Pemeriksaan makro terhadap permukaan patahan mempunyai bentuk patah statik dan dimulai dari bagian tengah lebar kawat. Pada Gambar 4 patah dari bagian dari sisi dalam coil, terlihat alur penjalaran patah/sobek mendadak. Retakan terlihat mengikuti alur dari arah coil pada saat operasi berlangsung. Analisa struktur mikro ini dilakukan untuk mengetahui adanya unsur cacat material, perubahanan struktur material, dan sebagai referensi bahwa Plate Wire tersebut layak untuk proses produksi. 


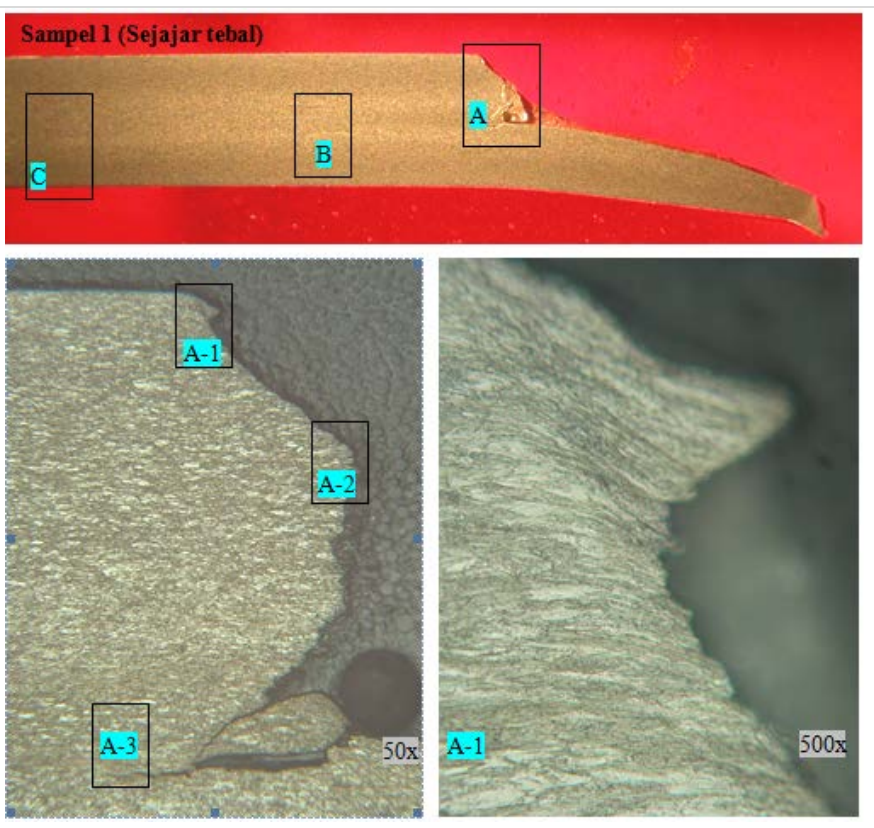

Gambar 5. Gambar struktur mikro sampel lokasi A.

Dapat dilihat struktur mikro sampel 1 dibagian patahanan (lokasi A-1 dan A-2) berupa perlitik dan mempunyai bentuk patah statik, pada lokasi A-3 dibagian tengah mengalami penjalaran retak transgrannular cracking akibat adanya cacat material. Etsa: nital $2 \%$

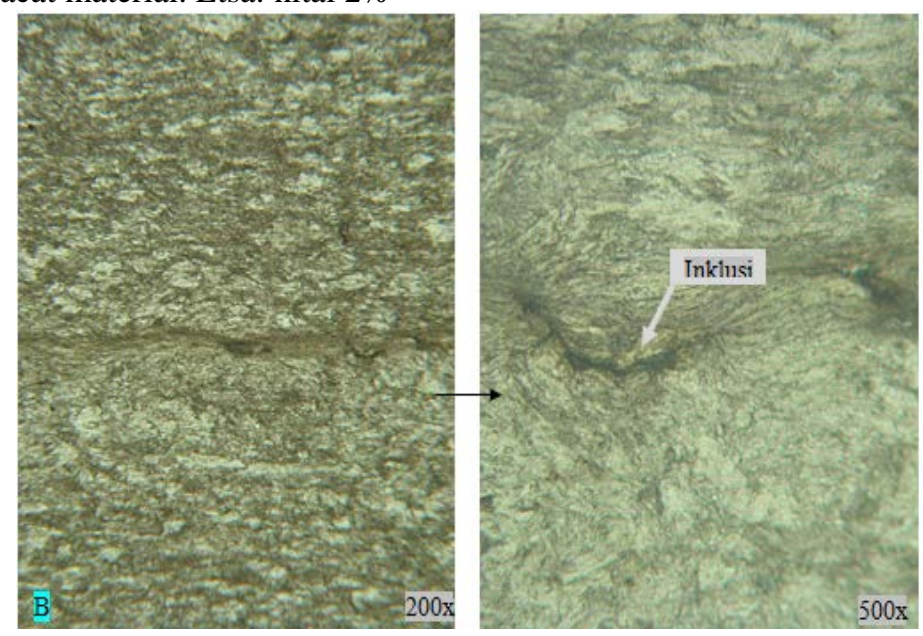

Gambar 6. Gambar struktur mikro sampel lokasi B.

Pada Gambar 6 lokasi B pada dibagian tengah mengalami cacat akibat proses roll, struktur mikro berupa matrik perlitik- ferrite dan adanya inklusi. Etsa:nital $2 \%$.

Pada Gambar 7 lokasi C dibagian tengah terdapat cacat material berupa inklusi, struktur mikro berupa matrik perlitik- ferrite. Etsa : nital 2\%.. Dari hasil pengamatan dapat diketahui bahwa secara makrografi hasil pemeriksaan secara visual dan makrografi pada permukaan patahan yang dimulai dari sisi bagian dalam coil, bentuk patah berupa patah statik. Ditemukan adanya cacat inklusi memanjang dibagian sisi tebal berupa inklusi. Pengamatan secara metalografi struktur mikro coil wire berupa perlitik dan ditemukan adanya cacat material yaitu inklusi bentuk memanjang arah pengerolan. 

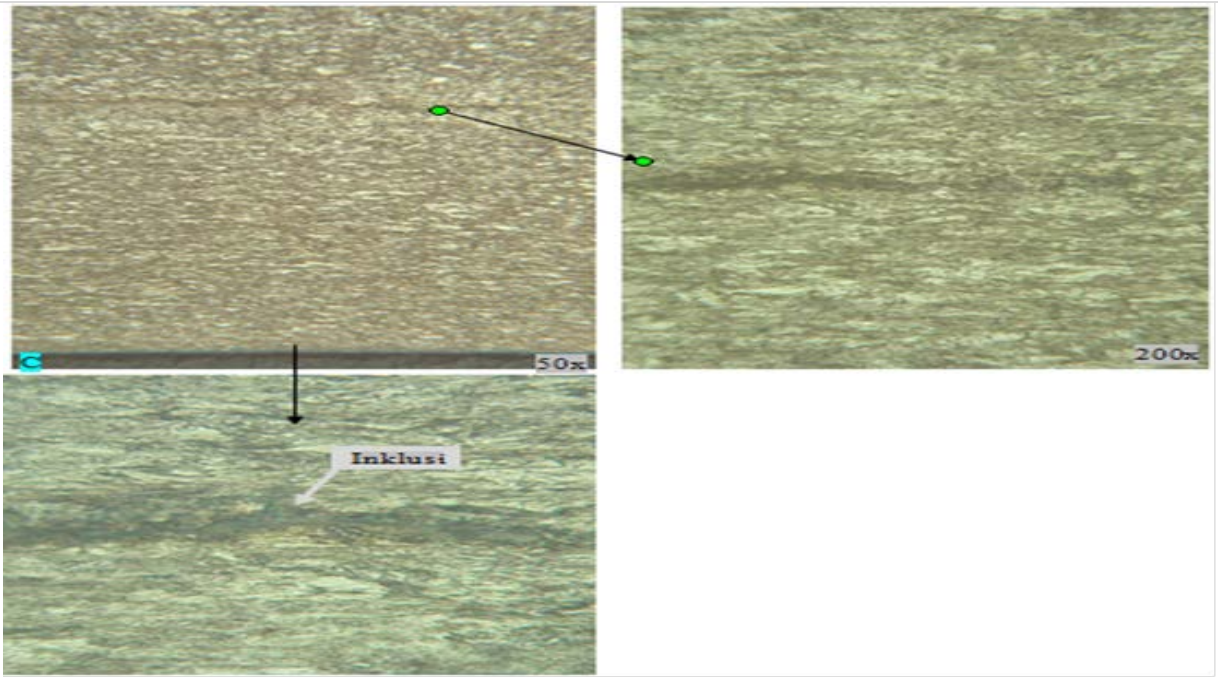

Gambar 7. Gambar struktur mikro sampel lokasi C.

Tabel 1. Hasil uji komposisi kimia material wire

\begin{tabular}{|c|c|c|}
\hline \multirow{2}{*}{ UNSUR } & \multicolumn{2}{|c|}{ KADAR ( \% ) } \\
\cline { 2 - 3 } & MATERIAL WIRE & STANDAR JISG4051 \\
\hline $\mathrm{C}$ & 0,648 & $0,42-0,48$ \\
\hline $\mathrm{Si}$ & 0,257 & $0,15-0,35$ \\
\hline $\mathrm{Si}$ & 0,001 & $<0,035$ \\
\hline $\mathrm{P}$ & 0,005 & $<0,03$ \\
\hline $\mathrm{Mn}$ & 0,685 & $0,6-0,9$ \\
\hline $\mathrm{Ni}$ & 0,017 & $<0,2$ \\
\hline $\mathrm{Cr}$ & 0,016 & $<0,2$ \\
\hline $\mathrm{Mo}$ & 0,011 & \\
\hline $\mathrm{V}$ & 0,011 & $<0,3$ \\
\hline $\mathrm{Cu}$ & 0,047 & \\
\hline $\mathrm{W}$ & 0,027 & \\
\hline $\mathrm{Ti}$ & 0,005 & \\
\hline $\mathrm{Sn}$ & 0,008 & \\
\hline $\mathrm{Al}$ & 0,015 & \\
\hline $\mathrm{Pb}$ & 0,035 & \\
\hline $\mathrm{Nb}$ & 0,024 & \\
\hline $\mathrm{Zr}$ & 0,021 & \\
\hline $\mathrm{Zn}$ & 0,161 & \\
\hline $\mathrm{Fe}$ & 98,01 & \\
\hline
\end{tabular}

Dari analisa komposisi kimia material wire , dapat ketahui bahwa:

1) Unsur karbon (C) pada (0,648 \% C) tidak sesuai dengan standar JIS G4051 2007 (0.42 0,48\%C),memperlihatkan perbedaan komposisi karbon yang signifikan sehingga mempengaruhi bertambahnya sifat kekerasan,tetapi mengurangi sifat tarik, elongasi, dan kekuatan impact. 
2) Unsur silikon (Si) pada wire (0,257\%Si) sesuai dengan standar JIS G4051 2007 (0,15 - 0.35\%Si), sehingga tidak mempengaruhi sifat material secara signifikan. Baja menjadi lemah jika kandungan silikon lebih dari $0,4 \%$.

3) Unsur sulfur (S) pada wire $(0.001 \% \mathrm{~S})$ sesuai dengan standar JIS G4051 2007 (0.035\%S) lebih rendah dari standart, dengan rendahnya unsur sulfur (S) pada material wire maka akan mempengaruhi sifat mampu mesin dan sifat kekerasannya. Sulfur dapat membuat baja menjadi getas pada temperatur tinggi, oleh karena itu dapat merugikan baja yang digunakan pada suhu tinggi. Umumnya kadar sulfur harus dikontrol serendah-rendahnnya, yaitu kurang dari 0,05\%.

4) Berdasarkan komposisi kimia unsur karbon melebihi standar baja karbon sedang sehingga aspek formability tidak memenuhi untuk pembuatan produk yang diinginkan,dan tergolong baja karbon tinggi.
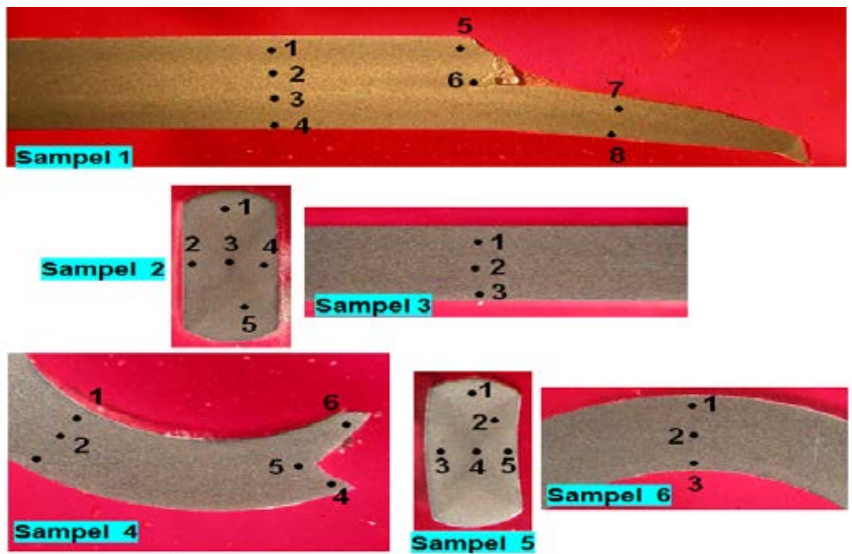

Gambar 4. Sampel uji kekerasan material Plate Wire

Tabel 2 Hasil uji kekerasan plate wire

\begin{tabular}{|c|c|c|c|c|c|c|c|}
\hline \multirow{2}{*}{ NO. } & \multicolumn{7}{|c|}{ NILAI KEKERASAN, HV } \\
\hline & Sampel 1 & Sampel 2 & Sampel 3 & Sampel 4 & Sampel 5 & Sampel 6 & Standar \\
\hline 1 & 441 & 454 & 485 & 492 & 492 & 515 & \multirow{8}{*}{$\begin{array}{l}\text { JIS } \\
\text { G4051 }\end{array}$} \\
\hline 2 & 485 & 466 & 485 & 478 & 500 & 492 & \\
\hline 3 & 492 & 523 & 472 & 507 & 585 & 507 & \\
\hline 4 & 441 & 500 & - & 472 & 505 & - & \\
\hline 5 & 435 & 454 & - & 478 & 494 & - & \\
\hline 6 & 441 & - & - & 485 & - & r- & \\
\hline 7 & 472 & - & - & - & - & - & \\
\hline 8 & 429 & - & - & - & - & - & \\
\hline $\begin{array}{l}\text { RATA- } \\
\text { RATA }\end{array}$ & 454,4 & 479,4 & 480,67 & 488,67 & 515,2 & 504,67 & $160-230$ \\
\hline
\end{tabular}

Berdasarkan Tabel 2 dapat dilihat bahwa nilai kekerasan yang tinggi material wire memiliki sifat getas yang tinggi pula sehingga material mudah patah ketika mendapat tegangan pada saat proses coiling. 


\section{KESIMPULAN}

1. Berdasarkan analisa laborat atau pengujian, menunjukan material wire mengalami cacat sehingga turunnya kemampuan sifat mekanis (sifat mampu mesin, elongasi) serta mampu mempengaruhi perubahan struktur mikro logam .

2. Berdasarkan pengamatan visual terhadap kerusakan yang lokasinya hampir sepanjang wire, kerusakan dipastikan akibat cacat material.

3. Berdasarkan hasil komposisi kimia material wire memiliki komposisi karbon yang tidak standar sehingga mempengaruhi turunnya kemampuan sifat mekanis (sifat kekerasan, sifat tarik, sifat mampu mesin, dan elongasi).

4. Nilai kekerasan yang tinggi melebihi standar mempengaruhi sifat material wire menjadi lebih getas.

\section{DAFTAR PUSTAKA}

[1] Daryanto, Ilmu Metalurgy. Satu nusa, Bandung, Oktober 2010

[2] Anrinal, Metalurgi fisik, Andi, Padang, Februari 2013

[3] D,N. Adnyana, Struktur dan Sifat Mekanis Material Logam, Diktat Mata Kuliah Program Pasca Sarjana (S2) ISTN Jakarta, 2003.

[4] Christopher J, Mc Cauley, Machinery's Handbook, 29th Edition, 2012

[5] Japanes Standards Association, Ferrous Material \& Metalurgy, JIS Hanbook, Japan 2007

[6] Drs.Edin Supardi, Pengujian Logam, Angkasaa, Bandung, 1994 